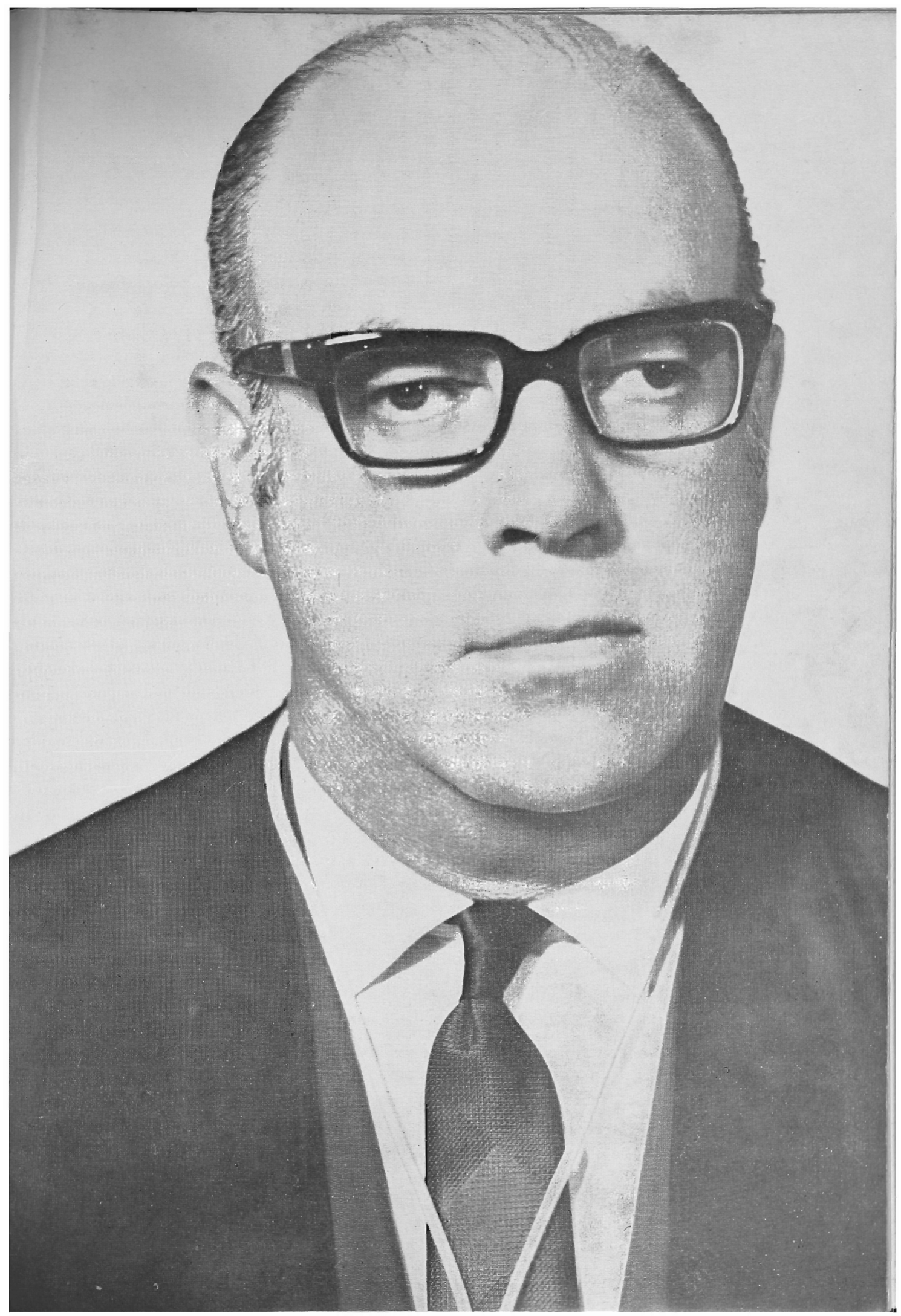


PROF. DR. MANOEL PEDRO PIMENTEL Nôvo Catedrático de Direito Penal 


\section{Dr. Manoel Pedro Pimentel, novo Catedrático de Direito Penal.}

O novo titular da cátedra de Direito Penal nasceu em Casa Branca, neste Estado, a $10^{\circ}$ de janeiro de 1922, filho de David Pimentel e Da. Adélia Pimentel.

Fêz o curso primário no Grupo Escolar "Arthur Guimarães", nesta Capital, tendo-o concluído em 1933. O Curso ginasial foi feito e concluido em 1939 no Colégio Arquidiocesano de São Paulo. Em 1940 ingressou no Colégio Universitário da Faculdade do Direito da U.S.P.. onde fêz o Curso Pré-Jurídico. Em 1942 ingressou no Curso de Bacharelado da mesma Faculdade, concluindo-o em 1946. Durante o curso foi eleito (em 1943) membro da Comissão de Redação do Centro Acadêmico "XI de Agôsto" e. nêsse mesmo ano (1943), foi eleito para a Academia de Letras da Faculdade de Direito da USP; ocupando a cadeira João Monteiro, e, em 1945, foi eleito Vice-Presidente dessa entidade.

Iniciou a vida profissional em 1945, como solicitador acadêmico. Trabalhou no escritório de advocacia do bel. Americo Marco Antonio, desde 1944 até 1950. Em 1951 instalou sua própria banca, especializando-se em Direito Penal. Em 1952 foi eleito membro do Conselho Secção de São Paulo da Ordem dos Advogados do Brasil, exercendo o cargo nos biênios de 1953/54, 55/56, 59/60. Foi convocado para substituir no mesmo Conselho, em 1957, sendo eleito, em 1958, para preencher a vaga ocorrida com a morte do Conselheiro Getúlio Paula Santos. No Conselho da Ordem integrou as Comissões de Disciplina 
e de Prerrogativas, tendo representado a Secção de São Paulo no $\mathrm{I}^{\circ}{ }^{\circ}$ Congresso Inter-Americano do Ministério Público, e no Congresso Internacional de Direito Penal e Penitenciário. Ainda como representante da Ordem, fêz parte das Comissões Examinadoras dos Concursos para ingresso na Magistratura, nos anos de 1958 e 1962, tendo integrado efetivamente a primeira e desligado da segunda pelo seu ingresso na Magistratura. Em 1961 foi eleito membro do Tribunal de Ética Profissional da Ordem dos Advogados do Brasil. Secção de São Paulo. Ainda como representante da mesma Ordem, fêz parte da Comissão de Reforma do Código de Processo Penal, organizada sob os auspícios do Govêrno do Estado, em 1959.

Por duas vêzes, foi eleito membro do Conselho Diretor da Associação dos Advogados de São Paulo, tendo alí ocupado os cargos de $2 .^{\circ}$ Secretário e de Vice-Presidente, exercendo interinamente a Presidência. Ocupou, ainda, o cargo de Diretor do seu Departamento de Cultura, organizando o "Curso Prático de Orientação Profissional", que ainda hoje é mantido.

Em 1957, a convite do Professor José Frederico Marques, ministrou aulas práticas de Direito Judiciário Penal, aos alunos do $5 .^{\circ}$ ano do Curso de Bacharelado da Faculdade de Direito da Pontificia Universidade Católica de São Paulo. Nêsse mesmo ano foi contratado como Auxiliar de Ensino da Faculdade de Direito da U.S.P., trabalhando junto à Cátedra de Direito Penal do Professor Noé Azevedo, ministrando aulas práticas às turmas dos Cursos Diurno e Noturno, organizando visitas aos estabelecimentos penais, ao Instituto de Polícia Técnica e a outras repartições policiais de interêsse, e ensejando às turmas a participação em trabalhos práticos de Júris Simulados.

Em 28 de junho de 1960 colou gráu de Doutor em Ciências Jurídicas e Sociais, aprovado em concurso para a Livre-Docência de Direito Penal, realizado nos dias 11 
a 15 de junho dêsse mesmo ano, em que apresentou a tese Crimes de mera conduta. Continuou no cargo de Auxiliar de Ensino, trabalhando junto à mesma Cátedra.

No dia 4 de abril de 1962 foi indicado, em lista tríplice organizada pelo Tribunal de Justiça do Estado de São Paulo, para preencher uma vaga de Juiz do Tribunal de Alçada, pelo quinto constitucional reservado para os advogados, tendo sido nomeado para êste cargo por decreto de 9 de abril seguinte, tomando posse em 26 do mesmo mês, integrando a Quarta Câmara Criminal da. quele Tribunal, da qual foi Presidente.

Em 1963 foi designado pela Congregação da Faculdade de Direito da U.S.P., para reger a cadeira de Direito Penal do $3^{\circ}$ ano do curso diurno de bacharelado, tendo merecido homenagem especial como professor da turma de bacharéis de 1964 .

Em 1964, ocupando o cargo de Diretor da Secção Penal da Biblioteca do Tribunal de Alçada, organizou o Caderno de Jurisprudência Criminal, que mereceu excelente aceitação. Ainda nessa qualidade, organizou, em 1965, uma "Estatística Criminal" dos feitos julgados pelo mencionado Tribunal, que foi recebida com agrado pelos setores especializados.

Em 1965 publicou, por intermédio da Editôra "Revista dos Tribunais", o livro Advocacia Criminal Teoria $e$ - Prática, que recebeu elogios da crítica, e encontra-se pronto para o lançamento, pela mesma Editôra, o trabalho Crimes de Mera Conduta.

10. Por deliberação da Egrégia Congregação da Faculdade de Direito da U.S.P., foi designado para a substituição do catedrático Prof. Noé Azevedo, por motivo de aposentadoria, passando a reger a Cadeira de Direito Penal do $3 .^{\circ}$ ano do Curso de Bacharelado, nos dois turnos.

Em 2 de outubro de 1967 foi eleito Presidente do Tribunal de Alçada Criminal, instalado nessa mesma data. 
Em junho de 1968 prestou concurso à Cétedra de Direito Penal da Faculdade de Direito da U.S.P., vaga pela aposentadoria do Prof. Noé Azevedo, apresentando a tese Do crime continuado, laureando-se com a média 8. 9, veio a ser nomeado Professor Catedrático em 19 de outubro dêsse mesmo ano.

Ainda nêste ano de 1968 publicou, através da Editôra "Lex", em calaboração com o Ministro José Luiz V. de Azevedo Franceschini, um excelente "Repertório de Jurisprudência Criminal do Tribunal de Alçada” 